\title{
Letter to the editor: Reply
}

\author{
Jung-Woo Shim and Min Suk Chae * (D)
}

\section{Dear Editor:}

We appreciate the valuable comments on our submitted article [1] provided by Löffel et al. We compared the analgesic outcomes on postoperative day (POD) 1 in patients undergoing robot-assisted laparoscopic prostatectomy (RALP) who received a rectus sheath block (RSB) or an intrathecal morphine and bupivacaine block (ITMB) with those of patients who received intravenous patient-controlled analgesia (IV-PCA) alone. Below are our responses to each comment.

In our hospital, we routinely provide a postoperative analgesic measure for a patient who underwent RALP. Patients can choose between ITMB with IV-PCA, RSB with IV-PCA, and IV-PCA only. Informed consent was obtained after detailed information about the advantages and disadvantages of each measure was discussed. Each analgesic protocol was administered to approximately $30 \%$ of patients, a finding that may be related to the distribution of the study population into three groups of 30 patients. Because we wanted to make sure that ITMB was superior to other pain control methods performed in our institution, we designed our study to investigate the severity of postoperative pain, as a primary outcome, according to the pain-relief methods. There is a risk of respiratory depression with ITMB. We are always concerned about this potentially life-threatening risk. This is the reason why we began the current study. We wanted to find out if RSB with IV-PCA has a comparable pain control efficacy to ITMB with IV-PCA.

The patients undergoing prostate surgery in our study, including RALP, were elderly (median [IQR] age $=65$ [62-71] years) [1]. Surgeons and physicians typically have clinical concerns regarding postoperative desaturation

This comment refers to the article available at https://doi.org/10.1186/ s12871-020-01208-2.

* Correspondence: shscms@gmail.com

Department of Anesthesiology and Pain Medicine, Seoul St. Mary's Hospital, College of Medicine, The Catholic University of Korea, 222, Banpo-daero, Seocho-gu, Seoul 06591, Republic of Korea due to atelectasis or residual effects of analgesic or anesthetic drugs, outside of our trial. In the ward, the patients' saturation was routinely monitored for $24 \mathrm{~h}$ postoperatively. During the study period, there were no episodes of desaturation related to respiratory depression thanks to meticulous monitoring and/or decreased opioid infusion, including intrathecal morphine $(0.2 \mathrm{mg})$ [2].

The minimum sample size was based on the difference in cumulative IV-PCA drug consumption on POD 1 between patients who received RSB and those who received ITMB, calculated using preliminary and retrospective data from electronic medical records. Mean cumulative IV-PCA drug consumption on POD 1 by patients who received RSB $(n=10)$ and those who received ITMB $(n=10)$ were 47.1 and $29.1 \mathrm{~mL}$, respectively. The standard deviation (SD) among the 20 patients was $23.6 \mathrm{~mL}$. Therefore, a minimum sample size of 27 patients/group was required to afford an $\alpha$ value of 0.05 and a power of 0.8 . We recruited 30 patients for each group assuming a dropout rate of $10 \%$ (these are demonstrated in the Statistical analysis section of our article) [1].

Our study was limited in that patients were not randomly allocated, despite the use of comparable groups. A randomized setting was considered but rejected due to ethical concerns that IV-PCA alone may provide insufficient pain relief compared with the other two analgesic regimens. Therefore, it was not possible to determine whether the analgesic results were solely related to the pain relief regimens. However, our study suggests that ITMB, as an analgesic protocol that targets both parietal and visceral pain, may contribute superior pain relief and better patient perception in terms of early postoperative recovery following RALP, which is a more advanced and less invasive surgical technique. Additional randomized studies are required to validate our analgesic results in the field of RALP.

(c) The Author(s). 2021 Open Access This article is licensed under a Creative Commons Attribution 4.0 International License, which permits use, sharing, adaptation, distribution and reproduction in any medium or format, as long as you give appropriate credit to the original author(s) and the source, provide a link to the Creative Commons licence, and indicate if changes were made. The images or other third party material in this article are included in the article's Creative Commons licence, unless indicated otherwise in a credit line to the material. If material is not included in the article's Creative Commons licence and your intended use is not permitted by statutory regulation or exceeds the permitted use, you will need to obtain permission directly from the copyright holder. To view a copy of this licence, visit http://creativecommons.org/licenses/by/4.0/ The Creative Commons Public Domain Dedication waiver (http://creativecommons.org/publicdomain/zero/1.0/) applies to the data made available in this article, unless otherwise stated in a credit line to the data. 


\section{Abbreviations}

POD: Postoperative day; RALP: Robot-assisted laparoscopic prostatectomy; RSB: Rectus sheath block; ITMB: Intrathecal morphine and bupivacaine block; IV-PCA: Intravenous patient-controlled analgesia

\section{Acknowledgements}

None.

\section{Authors' contributions}

J.W.S. and M.S.C. wrote the manuscript. All authors revised the manuscript critically for important intellectual content. All authors read and approved the final manuscript.

\section{Funding}

There are no grants and financial support to declare.

Availability of data and materials

Not applicable.

\section{Declarations}

Ethics approval and consent to participate

Not applicable.

\section{Consent for publication}

Not applicable.

\section{Competing interests}

No author has any conflict of interest regarding the publication of this article.

Received: 22 February 2021 Accepted: 11 March 2021

Published online: 17 March 2021

\section{References}

1. Shim JW, Cho YJ, Kim M, Hong SH, Moon HW, Hong SH, Chae MS. Comparison of analgesic efficacy between rectus sheath blockade, intrathecal morphine with bupivacaine, and intravenous patient-controlled analgesia in patients undergoing robot-assisted laparoscopic prostatectomy: a prospective, observational clinical study. BMC Anesthesiol. 2020;20(1):291. https://doi.org/10.1186/s12871-020-01208-2.

2. Nuri Deniz M, Erhan E, Ugur G. Intrathecal morphine reduces postoperative tramadol consumption in patients undergoing radical retropubic prostatectomy: a randomized trial. Eur Rev Med Pharmacol Sci. 2013;17(6):834-8.

\section{Publisher's Note}

Springer Nature remains neutral with regard to jurisdictional claims in published maps and institutional affiliations. 